\title{
Integrating Mobile-Assisted Language Learning: Teacher Beliefs in Japanese EFL Higher Education
}

\author{
Satchie Haga \\ Rikkyo University
}

\begin{abstract}
Internet-enabled mobile devices, such as tablets and smartphones have become an integral part of our lives. They are widely used for a variety of different purposes, and in many countries the majority of university students arrive to classes with devices and are familiar with how they operate. Although mobile technology is viewed to be a useful tool in language learning, there are a number of barriers to successful integration in classrooms. One of the critical factors when considering technology adoption is teacher attitudes and beliefs. However, despite the strong correlation of teacher attitudes and successful technology integration, the dominating interest of mobile-assisted language learning (MALL) research is on its relative effectiveness, or analyzes its adoption from the perspective of students. There is a lack of empirical studies that investigate variables related to teacher beliefs that affect mobile integration in the EFL context. This study explored teacher attitudes towards the implementation of mobile-assisted language instruction in higher education in Japan. 100 in-service teachers were given a questionnaire based heavily on the study by MacCallum, Jeffrey, \& Kinshuk (2014) that included extensions to the Technology Acceptance Model (TAM). The survey was adapted to include cultural variables related to English instructors teaching in an EFL context. The findings provide crucial insights into the cultural implications of teachers' perceptions towards the successful adoption of MALL for instruction. Implications for classroom practice in other contexts and professional development are discussed.
\end{abstract}

Keywords: bring your own device; instructional change; m-learning; Mobile technology integration; teacher attitudes 